\title{
Head size and growth in the very preterm infant: a literature review
}

\author{
This article was published in the following Dove Press journal: \\ Research and Reports in Neonatology \\ 6 January 2015 \\ Number of times this article has been viewed
}

\author{
Karla A Lee \\ Breda C Hayes \\ Rotunda Hospital, Dublin I, \\ Leinster, Ireland
}

Correspondence: Breda C Hayes Rotunda Hospital, Parnell Square,

Dublin I, Leinster, Ireland

Tel +353 I 8730700

Email bhayes@rotunda.ie
Objective: To review the literature investigating head size and examine head growth in relation to neurodevelopmental outcomes and neuroimaging data in the very preterm infant.

Methods: Systematic literature review of studies published in the following databases: PubMed/Medline, Cochrane Central Register of Controlled Trials (CENTRAL), Cumulative Index to Nursing and Allied Health (CINAHL), and Excerpta Medica dataBASE (EMBASE). Studies in the English language published between January 2005 and August 2013 were examined. Subjects were infants born at $\leq 32$ weeks of gestation. Main outcome measures included head growth, neurodevelopmental outcomes, and correlation between head size and neuroimaging.

Results: Thirty-four articles comprising 9,394 infants met inclusion/exclusion criteria. Of these, 31 studies $(6,592$ subjects) report head growth data measured at two or more time points. Neurodevelopmental outcome at $\geq 2$ years was reported by eleven studies ( 3,817 subjects). Nine studies (2,363 subjects) included neuroimaging data. Catch-up head growth was found to occur in the first year after birth. Poor nutrition was linked with poorer head growth. Small head size was associated with poor psychomotor and mental skills, higher rates of cerebral palsy, and autism. However, suboptimal head size at birth was not predictive of poor outcome, unless it persisted. Head size appears to correlate with brain volume at term. Associations between white matter abnormalities have been found by ultrasonography. In contrast, in magnetic resonance imaging (MRI) studies, gray matter seems to be the most susceptible to impairments during postnatal growth.

Conclusion: Head growth in early neonatal life is of importance. Avoiding growth impairment during neonatal care may allow for optimal cortical development. Many factors impact upon early head growth, particularly appropriate nutrition. There is no clear correlation between neuroimaging and head growth and this is an area deserving future research.

Keywords: head growth, head size, outcome, premature

\section{Introduction}

Preterm birth is associated with high rates of neonatal mortality and long-term morbidity. Significant advances over the past 2 decades have led to a dramatic increase in survival rates among extremely premature infants. ${ }^{1}$ As survival of these neonates is assured, there is a shift of attention toward their growth and development. Motor outcomes have improved, yet mental outcomes remain unchanged. ${ }^{2}$

Multiple reports have described associations between head size and neurodevelopmental outcome. ${ }^{3}$ Occipitofrontal circumference (OFC) is believed to reflect intracranial volume $e^{4}$ and correlate with actual brain size. ${ }^{5}$ Therefore, head growth is 
often seen as a proxy for brain growth and neurodevelopment. Suboptimal head growth and microcephaly at its extreme are common among preterm infants and longitudinal monitoring of this condition is important as it may predict neurological outcomes. Clinicians strive to promote growth, and where this has failed, strive to accelerate catch-up growth. In neonatology, the association between poor growth and neurodevelopmental outcome adds particular impetus to this practice.

The aim of this review was to evaluate three specific aspects of head size in very preterm infants: 1) head growth and factors affecting this 2) relationship between head size and neurodevelopmental outcomes; and 3) correlation between head size and neuroimaging.

\section{Methods}

A systematic review was undertaken by means of electronic searches of literature indexed in the following databases: PubMed/Medline, Cochrane Central Register of Controlled Trials (CENTRAL), Cumulative Index to Nursing and Allied Health (CINAHL), and Excerpta Medica dataBASE (EMBASE). The search was conducted using all combinations of the keywords ("preterm"), ("neonate" OR "infant" OR "baby"), ("head"), ("circumference" OR "size" OR "OFC" OR "occipitofrontal circumference"), and ("outcomes" OR "results" OR "growth" OR “development"). References and bibliographies from retrieved articles were also examined, but unpublished studies were not sourced. The search for papers to be included in the current study concluded in late August 2013. Exclusion criteria were non-English language papers, studies published prior to January 2005, and papers in which subjects were not specified to be $\leq 32$ weeks completed gestation. There were no restrictions based on methods of data collection or study design. A total of 34 articles met inclusion/exclusion criteria (Figure 1).

\section{Results}

Of these 34 papers (9,394 subjects), 31 studies (6,592 subjects) evaluated head growth using at least two time points, ${ }^{6-36}$ with retrospective or prospective head growth being part of the primary outcome in nine studies. ${ }^{7,8,18,19,21-23,27,33}$ Neurodevelopmental outcome at $\geq 2$ years was reported in eleven studies (3,817 subjects). ${ }^{7,9,10,12,14,18,19,21,27,28,36}$ Nine studies (2,363 subjects) included neuroimaging data, four of which report magnetic resonance imaging (MRI) data. ${ }^{7,30,32,35}$ Infants born at $\leq 28$ weeks gestation (Table S1) were examined in 12 studies, while 22 studies focused on infants of $>28$ weeks completed gestation (Table S2).

\section{Head growth}

Head growth after birth was poor, with the median standard deviation (SD) score for OFC decreasing from birth to discharge and further decreasing at follow-up. ${ }^{13,14,27}$ In a study ${ }^{27}$ of 488 children born at $<32$ weeks gestation, $57.8 \%$ were categorized as having suboptimal OFC ( $>1$ SD below mean)

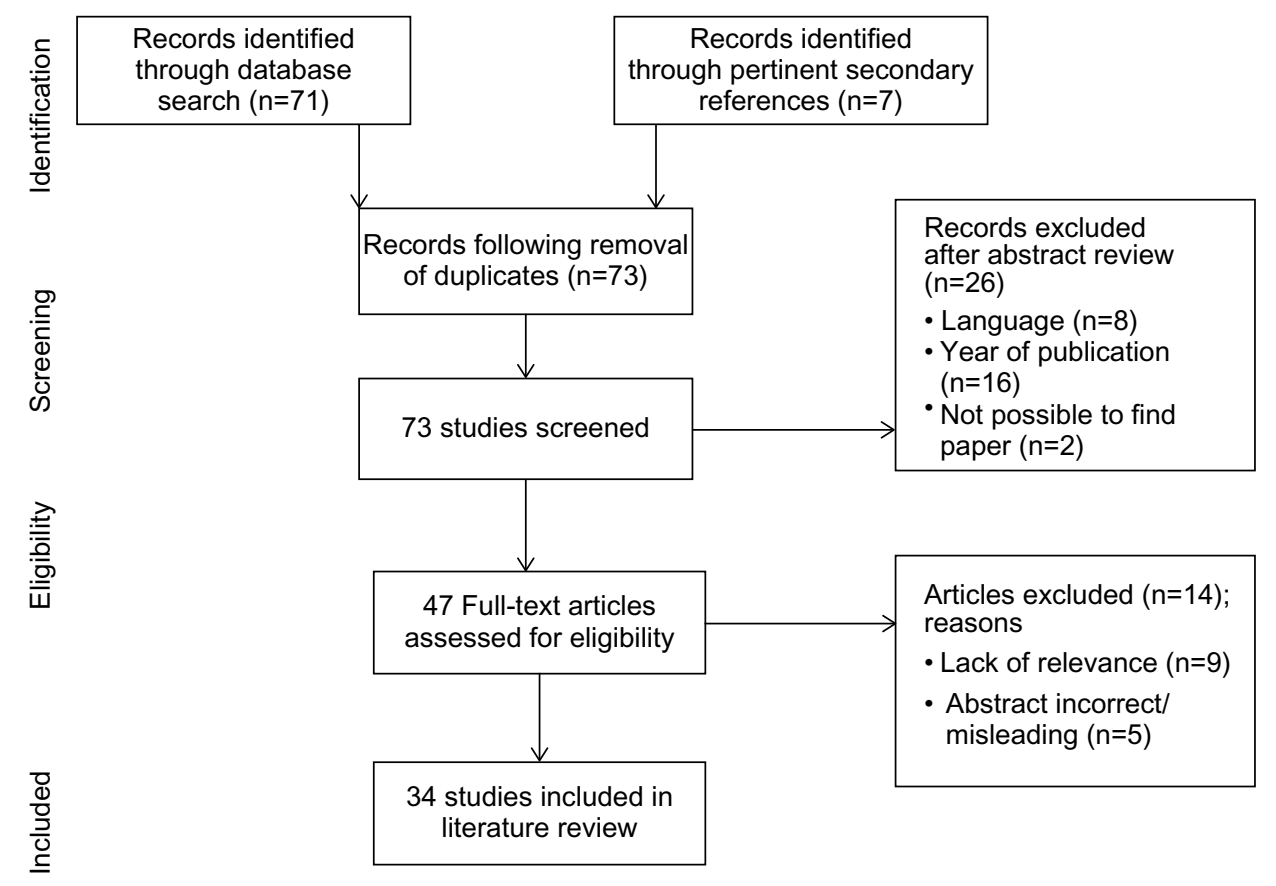

Figure I Flow of information through the different phases of literature review. 
at the 2-year follow-up. Reported rates of microcephaly ( $>2$ SD below mean) ranged from $9.2 \%{ }^{27}$ to $11.5 \%{ }^{7}$ at birth and from $9.4 \%{ }^{20}$ to $29.7 \%{ }^{7}$ at 2 years.

OFC "catch-up" growth, ie, achieving constitutional growth after a reduction in growth rate associated with illness and malnutrition, ${ }^{37}$ is generally poor. However, a tendency for catch-up growth shortly before 40 weeks corrected gestational age has been noted. ${ }^{16}$ In addition, a single study ${ }^{19}$ has reported $71 \%$ of children born with congenital microcephaly were no longer considered to be microcephalic at 24 months. Neubauer et $\mathrm{al}^{27}$ observed maximal OFC catch-up growth between discharge and 3 months. In keeping with studies evaluating early growth, Kytnarova et $\mathrm{al}^{20}$ reported that OFC catch-up growth decreases after the second year of life. In contrast to the above findings of poor extrauterine growth, Herrmann ${ }^{15}$ found that the $\mathrm{OFC}$ values remained $>10$ th percentile for intrauterine growth for all infants in their cohort, except those $<24$ weeks gestational age. Multiple studies ${ }^{6,16,20,21,29}$ have reported significantly poorer OFC catch-up growth at lower gestational ages (Table S1). The mean OFC at 6 years was found to increase by $0.21 \mathrm{SD}$ for each gestational week. ${ }^{6}$ Birth weight for gestational age has a significant independent additional effect on head size..$^{6,8,13,21,28}$ However, even at low gestational ages, significant brain-sparing effects of growth restriction were seen, ie, lower incidences of OFC growth restriction when compared to restrictions of height and weight. ${ }^{29,38}$

Factors other than gestational age were found to play a role in head growth in very preterm infants. Most studies found that sex but not ethnicity ${ }^{38}$ influences head size, with boys having a larger head size. However, Leviton et $\mathrm{al}^{21}$ found an association between microcephaly and children born to black or Hispanic mothers. Other factors found to influence head growth were severity of illness in the first hours after birth, ${ }^{10,31}$ duration of mechanical ventilation, pain scores, ${ }^{33}$ and nutrition. ${ }^{8,16,24,26,31,34,35}$ Although it is difficult to control for all medical confounders, previous studies showed an independent effect of postnatal steroids, both hydrocortisone ${ }^{32}$ and dexamethasone. ${ }^{28}$ Postnatal steroid exposure was shown to significantly increase the risk of microcephaly from $7.5 \%$ to $14 \%$ at term and from $29.7 \%$ to $38 \%$ at 2 years of age. ${ }^{7}$

The importance of growth factors was highlighted by two studies. Euser et $\mathrm{al}^{12}$ examined the effects of insulin-like growth factor-1 gene defects on cranial growth. Löfqvist et $\mathrm{al}^{23}$ illustrated that mean serum insulin-like growth factor-1 levels correlate with head growth and that a decline in postnatal head growth preceded the occurrence of proliferative retinopathy of prematurity.
Leviton et $\mathrm{al}^{21}$ identified a number of antenatal phenomena (eg, low-virulence organisms in placenta, tobacco exposure) and correlates of social class which influenced postnatal head growth. Of interest, preeclampsia/fetal indications to deliver preterm were associated with a greater risk of microcephaly compared to spontaneous onset of preterm labor. ${ }^{21}$

A number of studies ${ }^{16,31}$ linked poor head growth with poor caloric intake. Zachariassen et $\mathrm{al}^{34}$ found that fortification failed to significantly affect growth at 12 months of age. Significantly better head growth was reported from birth to 4 months in girls who were breastfed in combination with fortified expressed breast milk. Miller et al, ${ }^{26}$ in a randomized controlled trial of higher protein or control fortifier, found no significant differences in head growth. In their study, children were only followed up to discharge or corrected term age and OFC was not a primary outcome. In contrast to this, Biasini et $\mathrm{al}^{35}$ described higher Griffiths Mental Developmental Scales scores and an OFC growth advantage at 3 months and 9 months in infants of 23-30 weeks randomized to receive extra protein. In keeping with this finding, Maas et $\mathrm{al}^{24}$ reported an association between better postnatal head growth, high parenteral protein intake, and more rapid advancement of feeds in the first days of life; however, they failed to show a benefit at 3 weeks of life.

Herrmann ${ }^{15}$ reported favorable head growth $(81 \%$ of babies having $\mathrm{OFC}>10$ th intrauterine percentile by term age) in babies in receipt of $>50 \mathrm{kcal} / \mathrm{kg} /$ day of parenteral nutrition. Breast milk may also be advantageous. Cockerill et $\mathrm{al}^{8}$ associated accelerated postnatal head growth with breast milk despite poorer weight gain.

\section{Neurodevelopmental outcomes}

Suboptimal head size at birth did not predict outcome at any age in some studies. ${ }^{7,18}$ Likewise, congenital microcephaly may not be a risk factor for impairment unless it persists into the second year of life. ${ }^{19}$ In contrast, at 2 years and 8 years of age, OFC was reported to be strongly related to cognitive, academic, and motor outcomes. ${ }^{7,9}$ OFC catch-up growth between birth and 2 years of age was associated with a favorable neurodevelopmental profile at the age of 8 years; however, catch-up growth thereafter appeared to have minimal impact. ${ }^{18}$ Neubauer et al ${ }^{27}$ found 3 months corrected gestational age to be the time period at which head size was most strongly associated with psychomotor and mental outcomes. In keeping with these findings, Franz et $\mathrm{al}^{14}$ found that failure of in-hospital head growth was associated with adverse motor outcome at 5.4 years. Subnormal head size at 24 months, regardless of birth OFC, is associated with positive Modified 
Checklist for Autism in Toddlers (M-CHAT) screens at 2 years. ${ }^{19}$ Similarly, persistence of microcephaly at 3 years was associated with cerebral palsy and learning impairment at rates approximately three times greater than among children who never had microcephaly. ${ }^{19}$ Multiple tools were used to assess neurodevelopmental outcome at follow-up, and these are outlined in Tables S1 and S2.

Degree of head growth restriction is also of importance. Assessment scores on Bayley Scales of Infant Development ${ }^{39}$ at 24 months were significantly lower in infants with microcephaly ( $-2 \mathrm{SD})$ than in those with a small head (-1 SD). ${ }^{27}$ The key period of head growth that influences future neurodevelopment appears to be late pregnancy/early neonatal life. ${ }^{14}$ Microcephaly and the presence of abnormal imaging may confer an increased risk of developmental difficulties. Kuban et $\mathrm{al}^{19}$ demonstrated that white matter lesions combined with microcephaly places a patient at an 18-fold increased risk of cerebral palsy and an almost fourfold increased risk of poor psychomotor and mental processing scores.

\section{Neuroimaging}

Four studies ${ }^{7,30,32,35}$ included MRI data. In the study by Biasini et al, ${ }^{35}$ although 49 babies had MRI of the brain, only one baby had clearly pathological findings and therefore no data relating to head size and imaging is presented herein. In the study by Tan et al, ${ }^{30}$ significant numbers were lost to follow-up, with only $46 \%$ of infants enrolled having MRI. Therefore, data correlating MRI findings with head size are limited. However, the two remaining MRI studies ${ }^{7,32}$ did confirm a strong correlation between head size and brain tissue volume. Decreased brain volume at term in microcephalic babies appeared to be related to deep nuclear gray matter volume. ${ }^{7}$ Supporting this finding, Vinall et $\mathrm{al}^{32}$ found the gray matter to be most susceptible to impairments dur-

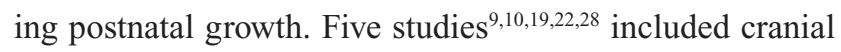
ultrasonography findings; however, ultrasonography data were correlated with OFC parameters in only three $9,19,28$ of these studies. In contrast to the MRI findings in the study of Cheong et al, ${ }^{7}$ wherein no significant differences in OFC were found between infants with different grades of white matter abnormalities, small head size was associated with significant white matter abnormalities on cranial ultrasonography in several studies. ${ }^{9,19,28}$

\section{Discussion}

This review was undertaken to evaluate literature investigating head size in the very preterm infant. Although many questions remain unanswered, suboptimal head size and/or growth which persists is clearly of importance. Most catch-up growth occurs in the first few months after birth, a time period spent in the neonatal intensive care unit for many of these infants. MRI studies associate small head size with reduced gray matter volume, whereas ultrasonography studies associate reduced head size with white matter injury. Whether or not head size can be influenced by dietary or environmental control or manipulation is unclear, as is the exact correlation between head size and brain volume.

Study standard was highly variable. The major strengths and weaknesses of each study are outlined in Tables S1 and S2. All but one study included herein defined their population by gestational age rather than birth weight. Cheong et $\mathrm{al}^{7}$ recruited infants with a birth weight of $<1,250 \mathrm{~g}$ or $<30$ weeks' gestation; however, the mean gestational age of subjects in that study was 27.4 weeks, with SD of 1.9 weeks, and therefore it is unlikely to have included many infants of $>32$ weeks. Eight studies $6,11,21,25,28,29,36,38$ accounted for size differences between different ethnic and racial groups, while social factors were considered in 15 studies. . $, 8,10,12-14,17,18,21,25,27,28,30,34,36 \mathrm{WHO}$ standards suggest one set of growth curves is appropriate for children throughout the globe; however, this may underestimate the rate of microcephaly and overestimate the rate of large head size in Western European countries. ${ }^{40}$ Many studies did not comment on the growth reference charts utilized, and the diversity of growth references chosen is illustrated in Tables S1 and S2. No study commented on parental OFC. The majority of studies did not comment on the respective methods of OFC measurement. Potential inaccuracy and issues with repeatability may negatively affect results, particularly in cases in which OFC growth was not a primary end point. In addition, studies were limited by the number and timing of head measurements. Birth head circumference and head size at 24 months were well documented. Data outlining interim OFC measurements were not available and therefore it is not possible to comment on peak time of head growth. Almost $50 \%$ of included studies omitted the range of gestational age and include only the upper gestational age in their work; this is reflected in Tables S1 and S2.

Eighteen ${ }^{6,9-13,17-19,21-23,25,28,29,34,38,41}$ of the 34 studies included were multicentered in nature, improving the generalizability of results. More than half of the 34 papers meeting inclusion criteria were prospective observational studies $7,8,10-13,15,17,19-23,27,28,32,33,35,41,42$ and were therefore subject to a number of confounding factors. Only five studies ${ }^{25,26,30,31,34}$ were randomized controlled trials. Four studies ${ }^{10,19,21,22}$ used the Extremely Low Gestational Age Newborn (ELGAN) cohort. Tan et $\mathrm{al}^{30,31}$ used the 
same group of infants for their two papers. Thirteen studies examined infants born at $\leq 28$ weeks gestation (Table S1), while 23 studies focused on those of $>28$ weeks completed gestation (Table S2). The studies focusing only on those of $\leq 28$ weeks gestation were more likely to be multicentered in nature, presumably due to difficulties recruiting large cohorts at this gestation.

The importance of head growth in the early neonatal period is clear, with microcephaly at birth being less significant compared with a small OFC beyond the neonatal period. ${ }^{7,13,20,27}$ Avoiding growth impairment during neonatal care may allow for optimal cortical development and ultimately provide an opportunity to decrease the rates of neurological disabilities related to preterm birth. However, studies focusing on the relationship between nutrition and head size are limited by small sample size. Three ${ }^{16,26,35}$ of these studies studied samples of $<100$ subjects. Six studies ${ }^{15,24,26,31,34,35}$ used control/comparison groups to investigate a nutritional intervention. Only two of these studies ${ }^{15,35}$ found statistical significance in their general or primary end points. More aggressive/high-protein feeding regimes were well tolerated in the short term ${ }^{24,31,35}$ but enhanced nutritional input may negatively affect later cardiovascular and metabolic risk. ${ }^{15,35,43}$ These risks need to be balanced against the need for reasonable postnatal growth, particularly head growth. There is no gold standard nutritional regimen for very preterm infants and the "optimal" growth of very preterm infants is not yet known. Whether additional nutritional efforts will not only prevent growth failure but also improve neurodevelopment remains uncertain.

There are currently no imaging correlates for the spectrum of neurocognitive impairments seen in preterm infants. A neuroimaging study ${ }^{44}$ has shown structural differences in the brain between growth-restricted premature infants and term controls, with reductions in both white and gray matter volumes. In another study, ${ }^{44}$ microcephaly was associated with a reduction in the volumes of all brain tissue types; however, the deep nuclear gray matter appeared to be especially vulnerable. In keeping with this, Cheong et $\mathrm{al}^{7}$ showed that smaller head size is associated with reduced deep nuclear gray matter volumes. In contrast, associations between white, rather than gray, matter abnormalities have been found on ultrasonography. ${ }^{9,19,28}$ This likely represents the limitations of ultrasonography in the determination of gray matter injury. Associations between microcephaly and poorer cognitive outcomes would be in keeping with abnormal gray matter development. Although Cheong et $\mathrm{al}^{7}$ demonstrated a clear correlation among head measurement, brain volume on MRI, and later developmental outcomes, further MRI research is needed to fully outline the relationship between head size and brain volumes in this population.

The population evaluated in this review is a heterogeneous group with significant differences existing between a 32-week infant and a 24-week infant. Given the degree of heterogeneity among studies, a meta-analysis was not possible. Another limiting factor was the exclusion of non-English language studies. This review excluded papers published prior to January 2005. Due to changes in neonatal intensive care practices, papers published prior to 2005 are more likely to include cohorts that may not be comparable to infants treated in the current medical era. However, it is acknowledged that a small number of studies ${ }^{6,9,12,13,18,20}$ reporting long-term follow-up included infants born a number of years before 2005. Most notably, Euser et $\mathrm{al}^{12}$ recruited his cohort of infants in the mid-1980s and followed them to the age of 19 years.

Suboptimal head size at birth is not predictive of poor neurodevelopmental outcome at any age, unless it persists. Small head size outside of the neonatal period is associated with poor psychomotor and mental skills at all gestational ages studied. The risk of poor developmental outcome is increased in microcephaly associated with abnormal neuroimaging and/or growth restriction. Inadequate nutrition in the early neonatal period is linked with poorer head growth, as are other factors such as steroid use, certain antenatal phenomena, and pain scores. While there appears to be a correlation among head measurement, deep nuclear gray matter volume on MRI, and later developmental outcomes, further research is needed to fully outline the relationship between head size and brain volumes. There is a need for focused, high-quality, prospective cohort studies to fully understand how to optimize head growth and subsequent neurodevelopmental outcomes in this vulnerable population.

\section{Disclosure}

The authors report no conflicts of interest in this work.

\section{References}

1. El-Metwally D, Vohr B, Tucker R. Survival and neonatal morbidity at the limits of viability in the mid 1990s: 22 to 25 weeks. J Pediatr. 2000;137(5):616-622.

2. Wilson-Costello D, Friedman H, Minich N, et al. Improved neurodevelopmental outcomes for extremely low birth weight infants in 2000-2002. Pediatrics. 2007;119(1):37-45.

3. Hack M, Breslau N, Fanaroff AA. Differential effects of intrauterine and postnatal brain growth failure in infants of very low birth weight. Am J Dis Child. 1989;143(1):63-68.

4. Bray PF, Shields WD, Wolcott GJ, Madsen JA. Occipitofrontal head circumference - an accurate measure of intracranial volume. $J$ Pediatr. 1969;75(2):303-305. 
5. Cooke RW, Lucas A, Yudkin PL, Pryse-Davies J. Head circumference as an index of brain weight in the fetus and newborn. Early Hum Dev. 1977;1(2):145-149.

6. Bracewell MA, Hennessy EM, Wolke D, Marlow N. The EPICure study: growth and blood pressure at 6 years of age following extremely preterm birth. Arch Dis Child Fetal Neonatal Ed. 2008;93(2):F108-F114.

7. Cheong JL, Hunt RW, Anderson PJ, et al. Head growth in preterm infants: correlation with magnetic resonance imaging and neurodevelopmental outcome. Pediatrics. 2008;121(6):e1534-e1540.

8. Cockerill J, Uthaya S, Dore CJ, Modi N. Accelerated postnatal head growth follows preterm birth. Arch Dis Child Fetal Neonatal Ed. 2006;91(3):F184-F187.

9. Cooke RW. Perinatal and postnatal factors in very preterm infants and subsequent cognitive and motor abilities. Arch Dis Child Fetal Neonatal Ed. 2005;90(1):F60-F63.

10. Dammann O, Naples M, Bednarek F, et al. SNAP-II and SNAPPE-II and the risk of structural and functional brain disorders in extremely low gestational age newborns: the ELGAN study. Neonatology. 2010;97(2): 71-82.

11. Diekmann M, Genzel-Boroviczeny O, Zoppelli L, von Poblotzki M. Postnatal growth curves for extremely low birth weight infants with early enteral nutrition. Eur J Pediatr. 2005;164(12):714-723.

12. Euser AM, Finken MJ, Kharagjitsingh AV, et al. IGF1 promoter polymorphism and cranial growth in individuals born very preterm. Horm Res Paediatr. 2011;76(1):27-34.

13. Farooqi A, Hagglof B, Sedin G, Gothefors L, Serenius F. Growth in 10- to 12 -year-old children born at 23 to 25 weeks' gestation in the 1990s: a Swedish national prospective follow-up study. Pediatrics. 2006;118(5):e1452-e1465.

14. Franz AR, Pohlandt F, Bode H, et al. Intrauterine, early neonatal, and postdischarge growth and neurodevelopmental outcome at 5.4 years in extremely preterm infants after intensive neonatal nutritional support. Pediatrics. 2009;123(1):e101-e109.

15. Herrmann KR. Early parenteral nutrition and successful postnatal growth of premature infants. Nutr Clin Pract. 2010;25(1):69-75.

16. Horemuzova E, Soder O, Hagenas L. Growth charts for monitoring postnatal growth at NICU of extreme preterm-born infants. Acta Paediatr. 2012;101(3):292-299.

17. Itabashi K, Mishina J, Tada H, Sakurai M, Nanri Y, Hirohata Y. Longitudinal follow-up of height up to five years of age in infants born preterm small for gestational age; comparison to full-term small for gestational age infants. Early Hum Dev. 2007;83(5):327-333.

18. Kan E, Roberts G, Anderson PJ, Doyle LW. The association of growth impairment with neurodevelopmental outcome at eight years of age in very preterm children. Early Hum Dev. 2008;84(6):409-416.

19. Kuban KC, Allred EN, O'Shea TM, et al. Developmental correlates of head circumference at birth and two years in a cohort of extremely low gestational age newborns. J Pediatr. 2009;155(3): e341-e343.

20. Kytnarova J, Zlatohlavková B, Kubena A, et al. Post-natal growth of 157 children born as extremely premature neonates. J Paediatr Child Health. 2011;47(3):111-116.

21. Leviton A, Kuban K, Allred EN, et al. Antenatal antecedents of a small head circumference at age 24 -months post-term equivalent in a sample of infants born before the 28th post-menstrual week. Early Hum Dev. 2010;86(8):515-521.

22. Leviton A, Kuban KC, Allred EN, Fichorova RN, O'Shea TM, Paneth N. Early postnatal blood concentrations of inflammation-related proteins and microcephaly two years later in infants born before the 28th postmenstrual week. Early Hum Dev. 2011;87(5):325-330.

23. Löfqvist C, Engström E, Sigurdsson J, et al. Postnatal head growth deficit among premature infants parallels retinopathy of prematurity and insulin-like growth factor-1 deficit. Pediatrics. 2006;117(6): 1930-1938.

24. Maas C, Mitt S, Full A, et al. A historic cohort study on accelerated advancement of enteral feeding volumes in very premature infants. Neonatology. 2013;103(1):67-73.
25. Maguire CM, Veen S, Sprij AJ, Le Cessie S, Wit JM, Walther FJ. Effects of basic developmental care on neonatal morbidity, neuromotor development, and growth at term age of infants who were born at $<32$ weeks. Pediatrics. 2008;121(2):e239-e245.

26. Miller J, Makrides M, Gibson RA, et al. Effect of increasing protein content of human milk fortifier on growth in preterm infants born at $<31 \mathrm{wk}$ gestation: a randomized controlled trial. Am J Clin Nutr. 2012;95(3): 648-655.

27. Neubauer V, Griesmaier E, Pehbock-Walser N, Pupp-Peglow U, KiechlKohlendorfer U. Poor postnatal head growth in very preterm infants is associated with impaired neurodevelopment outcome. Acta Paediatr. 2013;102(9):883-888.

28. Rijken M, Wit JM, Le Cessie S, Veen S. The effect of perinatal risk factors on growth in very preterm infants at 2 years of age: the Leiden Follow-Up Project on Prematurity. Early Hum Dev. 2007;83(8): 527-534.

29. Sakurai M, Itabashi K, Sato Y, Hibino S, Mizuno K. Extrauterine growth restriction in preterm infants of gestational age $\leq 32$ weeks. Pediatr Int. 2008;50(1):70-75.

30. Tan M, Abernethy L, Cooke R. Improving head growth in preterm infants - a randomised controlled trial II: MRI and developmental outcomes in the first year. Arch Dis Child Fetal Neonatal Ed. 2008;93(5):F342-F346.

31. Tan MJ, Cooke RW. Improving head growth in very preterm infants a randomised controlled trial I: neonatal outcomes. Arch Dis Child Fetal Neonatal Ed. 2008;93(5):F337-F341.

32. Vinall J, Grunau RE, Brant R, et al. Slower postnatal growth is associated with delayed cerebral cortical maturation in preterm newborns. Sci Transl Med. 2013;5(168):168ra168.

33. Vinall J, Miller SP, Chau V, Brummelte S, Synnes AR, Grunau RE. Neonatal pain in relation to postnatal growth in infants born very preterm. Pain. 2012;153(7):1374-1381.

34. Zachariassen G, Faerk J, Grytter C, et al. Nutrient enrichment of mother's milk and growth of very preterm infants after hospital discharge. Pediatrics. 2011;127(4):e995-e1003.

35. Biasini A, Marvulli L, Neri E, China M, Stella M, Monti F. Growth and neurological outcome in ELBW preterms fed with human milk and extra-protein supplementation as routine practice: do we need further evidence? J Matern Fetal Neonatal Med. 2012;25(Suppl 4):72-74.

36. van der Lugt NM, Smits-Wintjens VE, van Zwieten PH, Walther FJ. Short and long term outcome of neonatal hyperglycemia in very preterm infants: a retrospective follow-up study. BMC Pediatr. 2010;10:52.

37. Prader A, Tanner JM, von HG. Catch-up growth following illness or starvation. An example of developmental canalization in man. J Pediatr. 1963;62:646-659.

38. Karna P, Brooks K, Muttineni J, Karmaus W. Anthropometric measurements for neonates, 23 to 29 weeks gestation, in the 1990s. Paediatr Perinat Epidemiol. 2005;19(3):215-226.

39. Harris SR, Megens AM, Backman CL, Hayes VE. Stability of the Bayley II Scales of Infant Development in a sample of low-risk and high-risk infants. Dev Med Child Neurol. 2005;47(12):820-823.

40. Juliusson PB, Roelants M, Hoppenbrouwers K, Hauspie R, Bjerknes R. Growth of Belgian and Norwegian children compared to the WHO growth standards: prevalence below -2 and above $+2 \mathrm{SD}$ and the effect of breastfeeding. Arch Dis Child. 2009;96(10):916-921.

41. Costeloe KL, Hennessy EM, Haider S, Stacey F, Marlow N, Draper ES. Short term outcomes after extreme preterm birth in England: comparison of two birth cohorts in 1995 and 2006 (the EPICure studies). BMJ. 2012;345:e7976.

42. Ahmad I, Nemet D, Eliakim A, et al. Body composition and its components in preterm and term newborns: a cross-sectional, multimodal investigation. Am J Hum Biol. 2010;22(1):69-75.

43. Singhal A. Early nutrition and long-term cardiovascular health. Nutr Rev. 2006;64(5 pt 2):S44-S49; discussion S72-S91.

44. Tolsa CB, Zimine S, Warfield SK, et al. Early alteration of structural and functional brain development in premature infants born with intrauterine growth restriction. Pediatr Res. 2004;56(1):132-138. 
Research and Reports in Neonatology

Dovepress

\section{Publish your work in this journal}

Research and Reports in Neonatology is an international, peer-reviewed, open access journal publishing original research, reports, editorials, reviews and commentaries on neonatal health. The manuscript management system is completely online and includes a very quick and fair

peer-review system. Visit http://www.dovepress.com/testimonials.php to read real quotes from published authors.

Submit your manuscript here: http://www.dovepress.com/research-and-reports-in-neonatology-journal 